\title{
Improvement of visual acuity in diabetic and nondiabetic patients after Nd:YAG laser capsulotomy
}

This article was published in the following Dove Press journal:

Clinical Ophthalmology

10 October 2013

Number of times this article has been viewed

\author{
Muhammed Tayyab Awan 1,2 \\ Muhammed Anwar Khan ${ }^{3}$ \\ Saba Al-Khairy ${ }^{1,4}$ \\ Samina Malik ${ }^{1,4}$ \\ 'Pak Lab and Diagnostic Center, \\ Karachi, Pakistan; ${ }^{2}$ School of \\ Biomedical Sciences, University \\ of Ulster, Coleraine, Northern \\ Ireland, UK; ${ }^{3}$ Department of Medical \\ Education, King Saud bin Abdul- \\ Aziz University of Health Sciences, \\ Riyadh, Saudi Arabia; ${ }^{4}$ Department of \\ Ophthalmology, Jinnah Post Graduate \\ Medical Center, Karachi, Pakistan
}

Correspondence: Muhammed Tayyab Awan

Pak Lab and Diagnostic Center, 63-2/H, Block 6, PECHS, Karachi 75I00, Pakistan Tel +923338508882

Fax +92 2134547222

Email tayawan7ı@yahoo.co.uk
Purpose: The aim of the study reported here was to compare the improvement of visual acuity (VA) of diabetic and nondiabetic patients after neodymium-doped yttrium-aluminum-garnet (Nd:YAG) laser capsulotomy.

Methods: In this prospective cohort study, 50 age- and sex-matched patients, comprising 25 nondiabetics and 25 diabetics (referred to as Group A and B, respectively), with posterior chamber poly(methyl methacrylate) non-foldable intraocular lens implants attending our clinic at Karachi for capsulotomy had pre- and postoperative measures of VA, posterior pole visibility, and grading of posterior capsular opacity as seen on slit-lamp examination. VA was recorded before and after performing standard capsulotomy.

Results: The postoperative (mean) VA in nondiabetics was $0.25,0.23$, and $0.21 \log$ MAR as compared with $0.25,0.25$, and $0.24 \log$ MAR in diabetics at 1 week, 1 month, and 6 months, respectively. $P$-values of $0.47,0.47$, and 0.24 , respectively, were determined, which were not significant. Preoperative VA improvement was recorded in $92 \%$ of diabetics in Group B and $96 \%$ of nondiabetics in Group A. Two (8\%) diabetic patients developed glaucoma and did not participate in the study further.

Conclusion: Remarkable improvement in VA was achieved in both Group A and B, but the Group A nondiabetics showed more improvement in best-corrected VA after Nd:YAG laser capsulotomy.

Keywords: diabetes, posterior capsule, capsule opacification, intraocular

\section{Background}

Posterior capsule opacification (PCO), also referred to as the "after cataract" or "secondary cataract," is the most common late postoperative complication of cataract intraocular lens (IOL) surgery. ${ }^{1-3}$ It occurs in up to approximately $50 \%$ of patients within 2-3 years of their cataract surgery. ${ }^{4-6}$ Diabetic patients undergoing cataract surgery are at higher risk of postoperative complications. Diabetic patients have been reported to develop significantly greater PCO after cataract surgery than nondiabetic patients; however, the stage of retinopathy and the systemic status of diabetes did not correlate with the degree of PCO. ${ }^{7}$

The current treatment of choice for PCO is neodymium-doped yttrium-aluminumgarnet (Nd:YAG) laser capsulotomy, which is an effective, safe, noninvasive procedure that does not require patient hospitalization. ${ }^{8,9}$ The procedure involves producing a central opening in the opacified posterior capsule, giving instantaneous results. ${ }^{10}$

There is a paucity of literature prospectively evaluating improvement in the visual acuity (VA) of diabetic and nondiabetic patients after Nd:YAG laser 
posterior capsulotomy. Therefore, this study was designed to compare the rate and degree of improvement in VA between these two groups of patients.

\section{Patients and methods Study design}

This was a prospective cohort unmasked study performed in a private setting. Study approval was obtained from the Ethics Filter Committee of the University of Ulster.

\section{Patients and data collection}

A total of 25 nondiabetic and 25 diabetic age- and sexmatched patients with posterior chamber poly(methyl methacrylate) (PMMA) non-foldable IOL implants were selected from among those attending our clinic using a non-probability convenience sampling technique. Patients included in the study gave their informed consent and were divided into two groups. Group A comprised nondiabetic subjects and was designated the non exposed group $(n=25)$. GroupB included subjects with a history of diabetes mellitus and was designated the exposed group ( $n=25$ eyes).

Inclusion criteria for Group B patients were glycosylated hemoglobin levels of $\geq 6 \%$ and use of diabetic treatment (oral hypoglycemic agents, insulin injection, or diet restriction). A week before the procedure, fasting blood glucose analysis was performed on all patients. Methods of treatment, duration of diabetes (for subjects in Group B), and ocular and systemic comorbidities were recorded. The inclusion criterion for patients of both groups regarding PCO was PCO of grade 3 or 4, according to Sellman and Lindstrom grading (Table 1). ${ }^{11}$ Exclusion criteria were opacities in the media other than posterior capsular opacity or not matching the criteria for capsulotomy treatment; that is, corneal scars, irregularities or edema that interfered with target visualization or made the optical breakdown

Table I Sellman and Lindstrom posterior capsule opacification (PCO) grades"

\begin{tabular}{ll}
\hline Grade & Definition \\
\hline $\mathrm{I}$ & $\begin{array}{l}\text { No or slight PCO without reduced red reflex, also no } \\
\text { pearls at all or pearls not to the IOL edge }\end{array}$ \\
2 & $\begin{array}{l}\text { Mild PCO reducing the red reflex, Elschnig pearls to } \\
\text { the IOL edge }\end{array}$ \\
3 & $\begin{array}{l}\text { Moderate fibrosis or Elschnig pearls inside IOL edge } \\
\text { but with a clear visual axis }\end{array}$ \\
4 & $\begin{array}{l}\text { Severe fibrosis or Elschnig pearls covering the visual } \\
\text { axis and severely reducing the red reflex }\end{array}$
\end{tabular}

Note: ( 1988 Elsevier Limited. Reproduced with permission from Tami R, Sellman TR, Lindstrom RL. Effect of a plano-convex posterior chamber lens on capsular opacification from Elschnig pearl formation. J Cataract Refract Surg. 1988; 14(I):68-72.

Abbreviation: IOL, intraocular lens.
Table 2 Madurai Intraocular Lens Study IV scale for optic disc visualization $^{12}$

\begin{tabular}{ll}
\hline Grade & Definition \\
\hline 0 & $\begin{array}{l}\text { Clear visibility of optic disc margins, blood vessels at the } \\
\text { optic disc, and nerve fiber layer }\end{array}$ \\
\hline & $\begin{array}{l}\text { Optic disc margins are clearly visible, but optic disc blood } \\
\text { vessels and/or nerve fiber layer are not clearly seen }\end{array}$ \\
2 & $\begin{array}{l}\text { Blurred visibility of margins of optic disc, blood vessels of } \\
\text { optic disc, and nerve fiber layer }\end{array}$ \\
\hline
\end{tabular}

Note: (๑ 2000 Elsevier Limited. Reproduced with permission from Venkatesh N, Prajna NV, Ellwein LB, Selvaraj S, Manjula K, Kupfer C. The Madurai Intraocular Lens Study IV: posterior capsule opacification. Am J Ophthalmol. 2000;।30(3):304-309.

unpredictable, and inadequate stability of the eye or relative contraindications such as glass IOL, known or suspected cystoid macular edema, active intraocular inflammation and high risk for retinal detachment. Prior to capsulotomy, the patient's visual function was recorded with their pupil in a normal physiological state in terms of best-corrected visual acuity (BCVA) using a Snellen VA chart kept at $6 \mathrm{~m} \mathrm{(20} \mathrm{ft)}$ from the patient's eyes.

Intraocular pressure (IOP) was measured. Pupil dilation was carried out with topical $1 \%$ tropicamide eye drops. The pupillary size was recorded after about 20 minutes using a millimeter scale and PCO was graded according to Sellman and Lindstrom grading (grades 1 to 4 ; Table 1). ${ }^{11}$

In case of dense posterior capsule opacity, B-scan ultrasonography was carried out to exclude any posterior segment pathology. Posterior pole assessment was performed with a Volk 90D lens (Volk Optical Inc, Mentor, OH, USA). The Madurai Intraocular Lens Study IV scale was used for grading of optic disc visualization (Table 2). ${ }^{12}$

Macula visualization was graded subjectively according to the scale used by Aslam and Patton (Table 3). ${ }^{13}$

\section{Nd:YAG laser capsulotomy}

All Nd:YAG laser capsulotomy procedures were performed on a Visulas ${ }^{\circledR}$ YAG II (Carl Zeiss Meditec, Jena, Germany). The wavelength of therapy beam was $1064 \mathrm{~nm}$. Radiation was produced by a Q-switched mode. It was initially set at $1 \mathrm{~mJ}$

Table 3 Macula visualization scale used by Aslam and Patton ${ }^{13}$

\begin{tabular}{ll}
\hline Grade & Definition \\
\hline 0 & $\begin{array}{l}\text { Clear view of foveal reflex, peri-foveal blood } \\
\text { vessels, and nerve fiber layer }\end{array}$ \\
& $\begin{array}{l}\text { Diminished foveal reflex, but clear view of peri- } \\
\text { foveal blood vessels and nerve fiber layer }\end{array}$ \\
2 & $\begin{array}{l}\text { Blurred foveal reflex, peri-foveal blood vessels, } \\
\text { and/or nerve fiber layer }\end{array}$ \\
\hline
\end{tabular}

Note: () 2000 BioMed Central. Reproduced with permission from Aslam TM, Patton N. Methods of assessment of patients for Nd:YAG laser capsulotomy that correlate with final visual improvement. BMC Ophthalmol. 2004;4:13. 


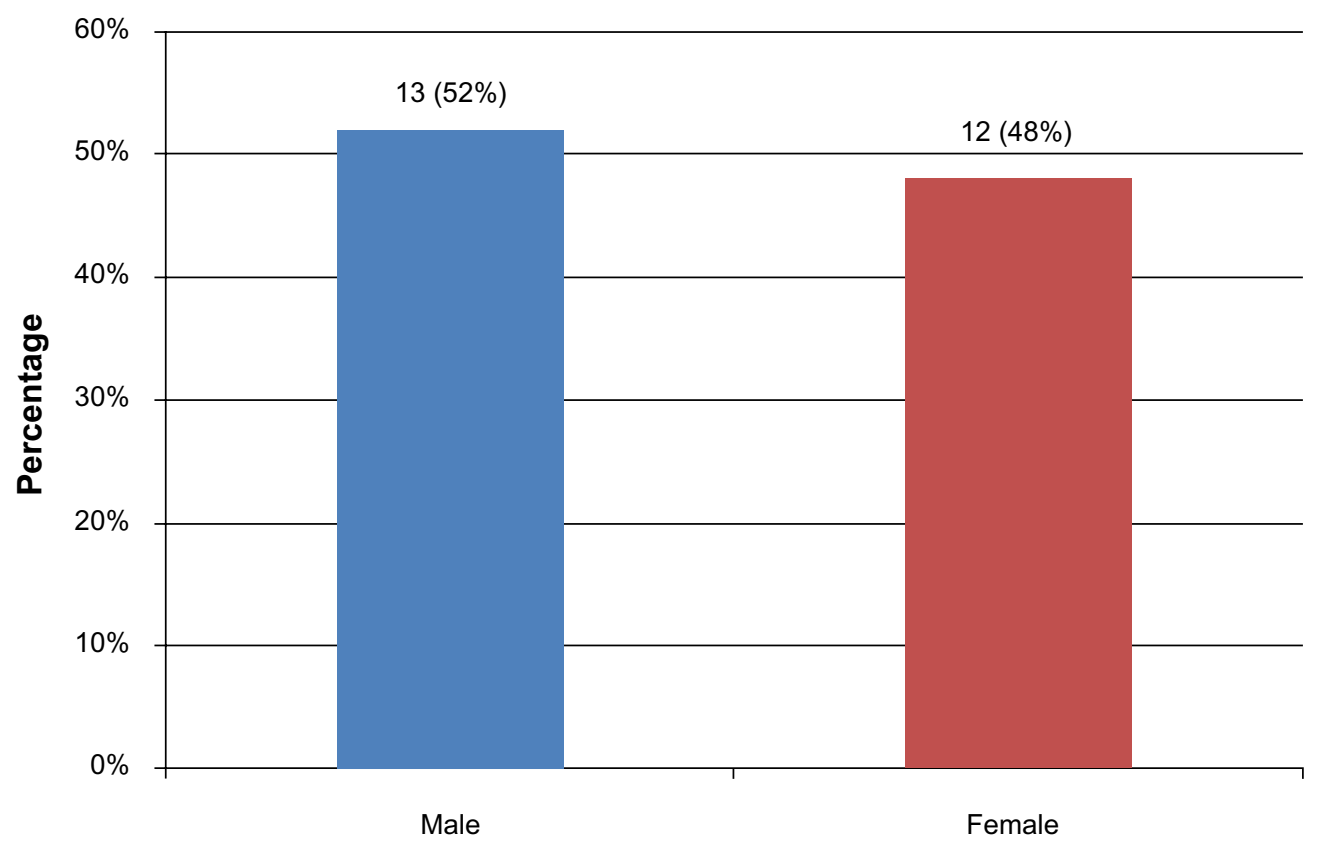

Figure I Sex distribution among nondiabetic patients $(n=25)$ in the study.

then subsequently raised to $5 \mathrm{~mJ}$ stepwise as necessary to pierce the posterior capsule. Capsulotomy was performed in a cross fashion; size of capsulotomy ranged between 3-4 mm. Once the procedure was completed, one drop of dexamethasone and one drop of levobunolol eye drops were instilled. When higher energy levels (4.5-6.0 mJ) were used, one tablet of acetazolamide (Tablet AZM $250 \mathrm{mg}$; Ethical Laboratories, Lahore, Pakistan) was also given immediately.
IOP was monitored for 1 hour following the procedure and then the patient was discharged on dexamethasone eye drops $0.1 \%$ four times daily and levobunolol eye drops twice daily. Post Nd:YAG laser treatment was continued for 2 weeks. Patients' visual function was reassessed again, as described earlier, on subsequent visits 1 day, 1 week, 1 month, 3 months, and 6 months after the procedure.

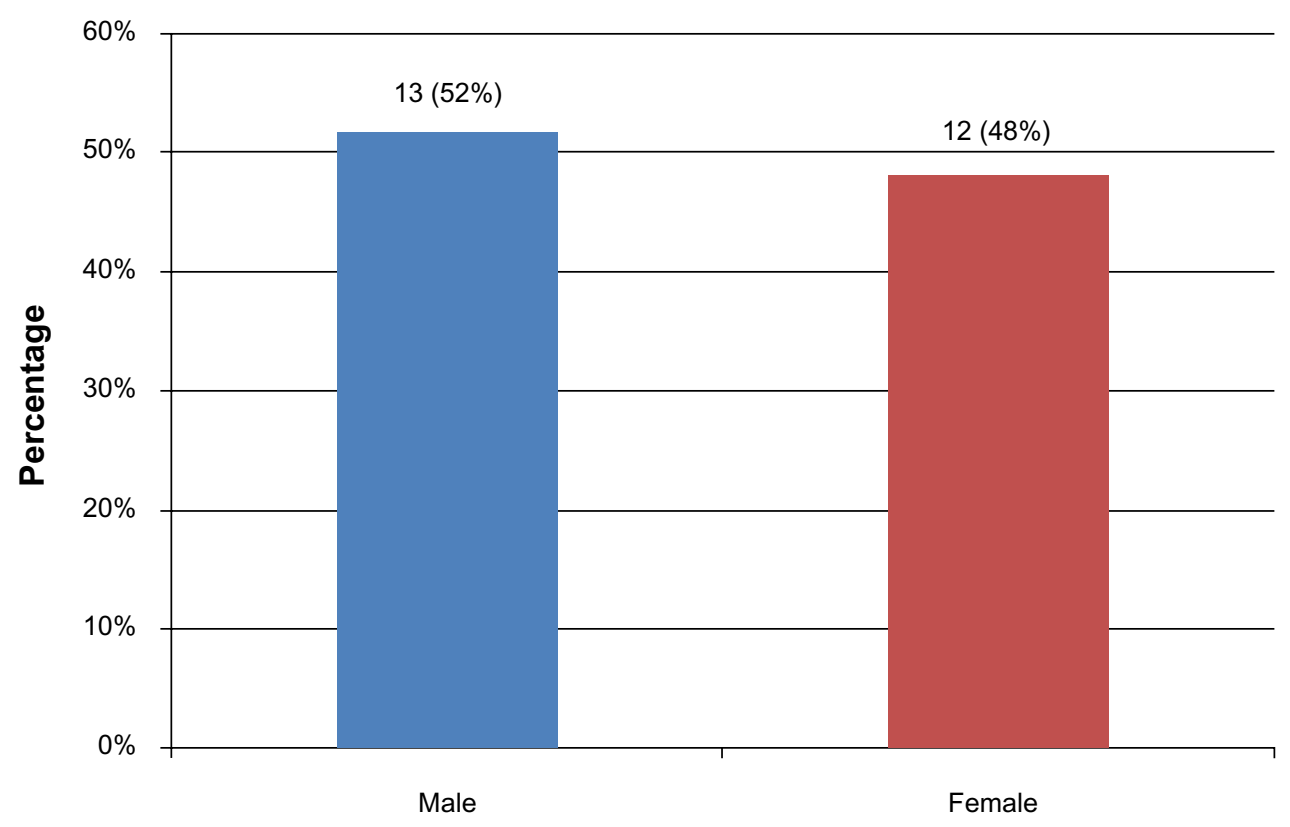

Figure 2 Sex distribution among diabetic patients $(n=25)$ in the study. 


\section{Diabetics $\square$ Nondiabetics}

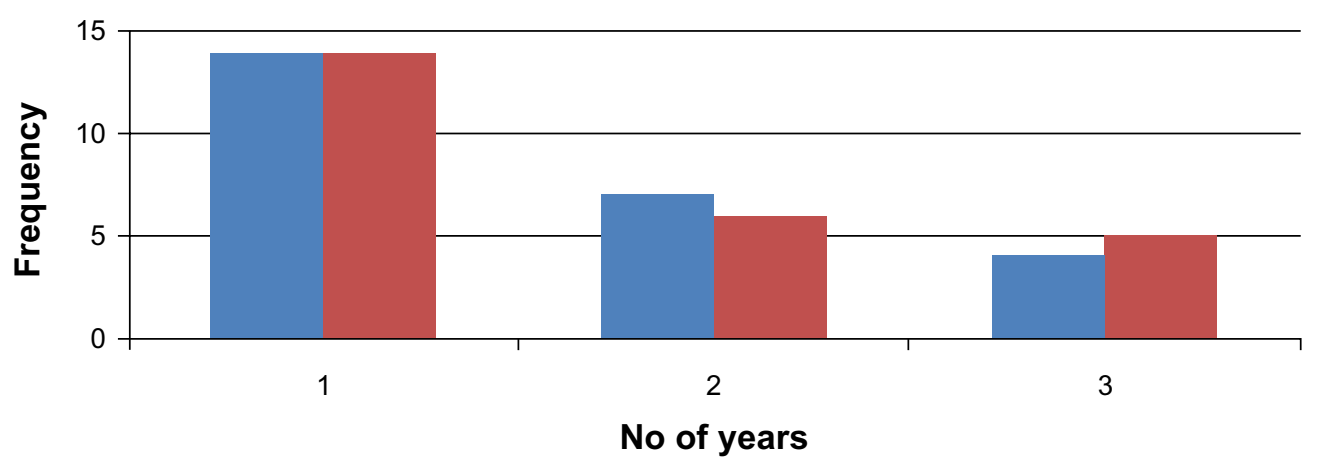

Figure 3 Comparison between nondiabetic $(n=25)$ and diabetic $(n=25)$ study groups of time elapsed since cataract surgery.

\section{Data analysis}

Data were entered into and analyzed with SPSS (v 11.0; IBM Corporation, Armonk, NY, USA). Frequency and percentage were computed for categorical variables like sex. The mean and standard deviation (SD) were estimated for quantitative variables such as post operative VA. For inferential statistics, the chi square test/Fisher exact test was used for the comparison of categorical variables, and for numerical variable $t$-test was used, such as type of PCO. $P$-value $<0.05$ was considered significant.

\section{Results}

Fifty patients, comprising 25 nondiabetic and 25 diabetic age- and sex-matched patients of South Asian origin with posterior chamber PMMA non-foldable IOL implants with PCO, of whom 24 were female, were examined and Nd:YAG laser capsulotomy was performed (Figures 1-2). The mean age $\pm \mathrm{SD}$ was $60.44 \pm 5.00$ and $60.52 \pm 5.00$ years for nondiabetics and diabetics, respectively. The mean period between cataract extraction and performing Nd:YAG laser capsulotomy was $16 \pm 2$ months (Figure 3). Capsular fibrosis was the predominant type of PCO (Table 4).

Similar ocular comorbid diseases were present in both groups. The most common systemic comorbid disorder found

Table 4 Types of posterior capsule opacification (PCO) in diabetics and nondiabetics $(N=50)$ with $P$ values

\begin{tabular}{lllll}
\hline Type of PCO & $\begin{array}{l}\text { Total } \\
\text { n (\%) }\end{array}$ & $\begin{array}{l}\text { Nondiabetics } \\
\text { n (\%) }\end{array}$ & $\begin{array}{l}\text { Diabetics } \\
\text { n (\%) }\end{array}$ & P-value \\
\hline Capsular fibrosis & $3 \mathrm{I}(62 \%)$ & I6 (64\%) & I5 (60\%) & 0.99 \\
Elschnig Pearls & II (22\%) & $5(20 \%)$ & $6(24 \%)$ & 0.99 \\
Capsular wrinkling & $6(12 \%)$ & $3(12 \%)$ & $3(12 \%)$ & 0.99 \\
Pigmentary deposits & $2(4 \%)$ & I (4\%) & I(4\%) & 0.99 \\
\hline
\end{tabular}

was hypertension. It was less common in nondiabetics (20\%) than in diabetics (58\%) (Table 5).

The minimum preoperative BCVA in both groups was not less than 6/60 (20/200) on the Snellen chart. Good VA results were noted more commonly in nondiabetic patients than in diabetic patients. However, this difference was not statistically significant. The mean \pm SD postoperative VA in nondiabetics was $0.25 \pm 0.09,0.23 \pm 0.09$, and $0.21 \pm 0.08 \log$ MAR at 1 week, 1 month, and 6 months, respectively (Figure 4), as compared with $0.27 \pm 0.10,0.24 \pm 0.09$, and $0.24 \pm 0.09$, respectively, in diabetics (Figure 5). In nondiabetics, 96\% $(24 / 25)$ of patients showed a mean \pm SD BCVA improvement of $0.21 \pm 0.08 \log$ MAR, while $4 \%(1 / 25)$ of patients showed a BCVA of $0.00 \log$ MAR after capsulotomy - that is, full visual recovery - while, for diabetics, the mean visual improvement was $0.24 \pm 0.09 \log$ MAR; $P=0.24$.

The (mean) postoperative improvement in VA between diabetic and nondiabetic patients after Nd:YAG was calculated by $t$-testing at 1 week, 1 month, 3 months, and 6 months following

Table 5 Frequency of comorbid systemic and ocular diseases in patients

\begin{tabular}{|c|c|c|c|}
\hline \multirow[t]{2}{*}{ Disease } & \multicolumn{3}{|c|}{ Frequency, n } \\
\hline & Diabetics & Nondiabetics & $P$-value \\
\hline Systemic hypertension & 14 & 5 & 0.02 \\
\hline Renal impairment & 0 & 0 & - \\
\hline Peptic ulcer disease & 1 & 0 & 0.99 \\
\hline $\begin{array}{l}\text { Chronic obstructive airway } \\
\text { disease }\end{array}$ & 0 & 2 & 0.50 \\
\hline \multicolumn{4}{|l|}{ Ocular } \\
\hline $\begin{array}{l}\text { Age-related macular } \\
\text { degeneration }\end{array}$ & 0 & 0 & - \\
\hline $\begin{array}{l}\text { Primary open-angle } \\
\text { glaucoma }\end{array}$ & 0 & 0 & - \\
\hline Pterygium & 0 & 0 & - \\
\hline Total & 15 & 7 & \\
\hline
\end{tabular}




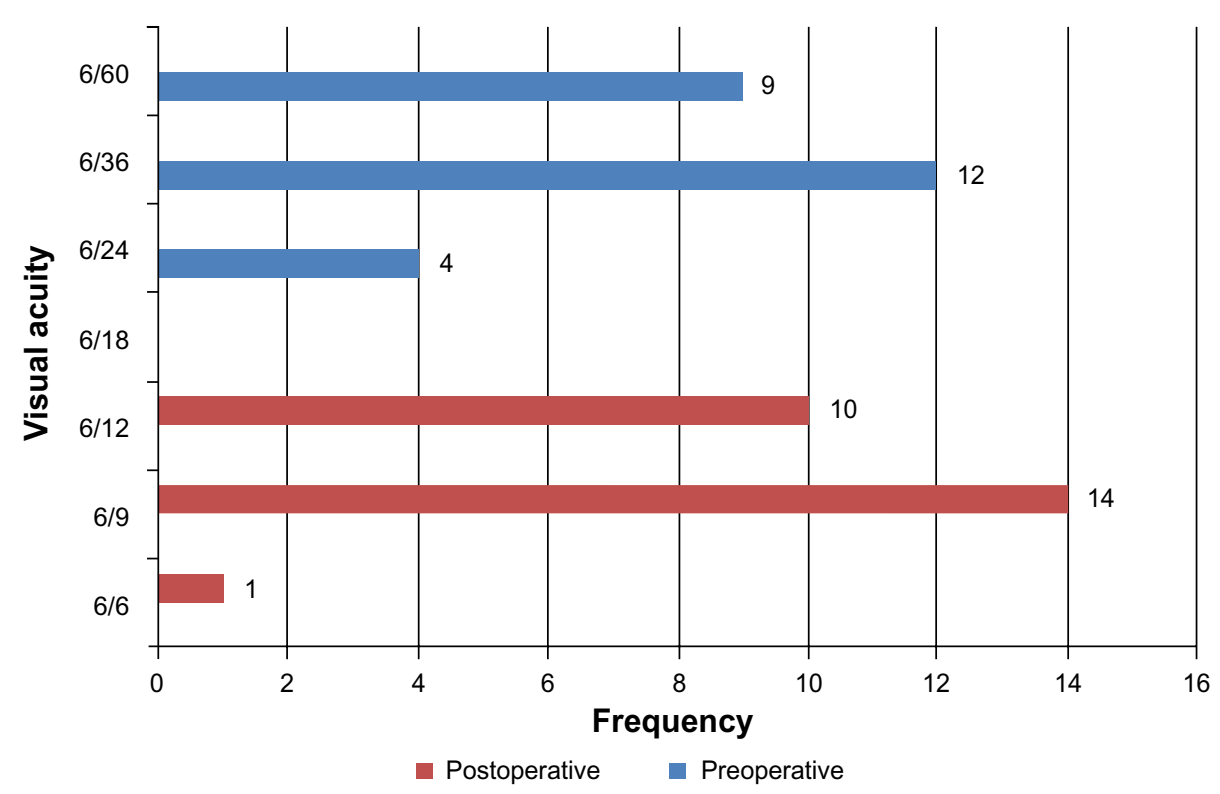

Figure 4 Comparison of pre- and postsurgical visual acuity among nondiabetic study participants $(\mathrm{n}=25)$.

the procedure. The $P$-value was 0.47 at 1 week and 1 month, and 0.24 at 3 and 6 months, none of which were significant.

No other complications were encountered, except two (8\%) patients in the diabetic group (4\% of the total study population) developed persistent raised IOP 24 hours after Nd:YAG laser, which finally culminated in glaucoma. These two patients did not participate in the study further. Later, it was established that they had undiagnosed open-angle glaucoma.
The mean postoperative improvement in VA of both groups is shown in Table 6 .

\section{Discussion}

Nd:YAG laser capsulotomy is indicated for the treatment of opacification of the posterior capsule resulting in decreased VA or visual function, or both. ${ }^{14}$ The period between cataract extraction and performing Nd:YAG laser capsulotomy was $16 \pm 2$ months in our study, while it was 3 years in the study

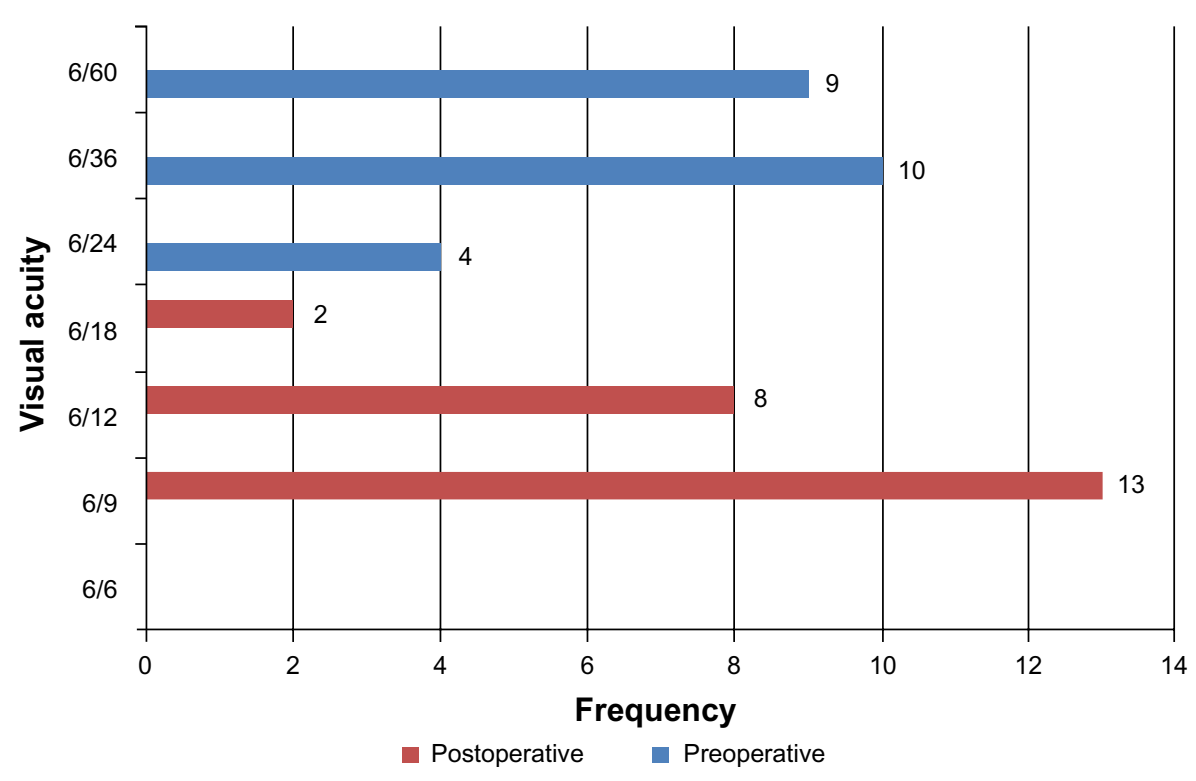

Figure 5 Comparison of pre- and postsurgical visual acuity among diabetic study participants $(\mathrm{n}=25)$. 
Table 6 Postoperative visual acuity after Nd:YAG laser capsulotomy (mean \pm standard deviation)

\begin{tabular}{llll}
\hline $\begin{array}{l}\text { Postoperative } \\
\text { period }\end{array}$ & Nondiabetic & Diabetic & P-value \\
\hline I week & $0.25 \pm 0.09 \log M A R$ & $0.27 \pm 0.10 \log M A R$ & 0.47 \\
I month & $0.23 \pm 0.09 \log M A R$ & $0.24 \pm 0.09 \log M A R$ & 0.47 \\
3 months & $0.21 \pm 0.08 \log M A R$ & $0.24 \pm 0.09 \log M A R$ & 0.24 \\
6 months & $0.21 \pm 0.08 \log M A R$ & $0.24 \pm 0.09 \log M A R$ & 0.24 \\
\hline
\end{tabular}

by Flach and Dolan. ${ }^{15}$ The relative incidence of different types of PCO showed that capsular fibrosis was the predominant type of $\mathrm{PCO}$; this finding is in contrast with the findings of Hassan et al, who reported Elschnig's pearls in pseudophakic eyes and secondary fibrosis in aphakic eyes. ${ }^{16}$

Hypertension, which was the most common comorbid disease, was found to be more prevalent in the diabetic group ( $58 \%$ vs $20.0 \%$ ). On applying chi-square test to calculate the $P$-values for co-morbidities it was found to be 0.02 for hypertension, which is significant, while for other co-morbidities (such as peptic ulcer disease and chronic obstructive airway disease) the $P$-values were 0.99 and 0.50 .

There was spectacular improvement in VA according to Snellen chart testing after Nd:YAG laser capsulotomy. In Group A (nondiabetics), $96 \%$ of patients improved from two to five lines on the Snellen chart, while a Snellen chart VA improvement of $2-5$ lines was recorded for $92 \%$ of Group B (diabetics). It was also noted that there was no further deterioration of VA in any case. In Hassan et al's study, Snellen chart VA improvement after Nd:YAG laser capsulotomy was 1-3 lines in 42 out of 86 (49\%) patients, 4-6 lines in 31 out of $86(36.04 \%)$ patients, and there was no VA improvement in $13(15.11 \%)$ cases due to comorbidities. ${ }^{16}$

We encountered complications in our study in only two patients from Group B who developed persistent raised IOP 24 hours after Nd:YAG laser capsulotomy. These two patients comprised $8 \%$ of the exposed group, which disagrees with Steinert et al, who estimated that the incidence of glaucoma developing after capsulotomy was $1 \%-6 \% .{ }^{17}$ Thus, incidence of rise in IOP was high in our study, despite all patients having posterior chamber IOL implantation, their being selected with normal IOP, and our use of very low energy levels in the capsulotomy procedure. No evidence of cystoid macular edema, retinal detachment, iritis, or corneal or IOL damage was noted in this series of Nd:YAG posterior capsulotomies. To prevent complications, all factors should be kept in mind, such as the power of the Nd:YAG laser being used, the focusing mechanism of the instrument, separation between posterior capsule and IOL, type of IOL, and the operator's experience.

\section{Limitations}

It is possible that the figures in this study are underestimated because the length of follow-up was short (ie, 6 months) and as the sample size of this study was also small.

\section{Conclusion}

Although there was equal chance of BCVA improvement in both groups, as the diabetic subjects had a greater risk of developing complications, improvement in BCVA was less in this group than in the nondiabetic group after Nd:YAG laser capsulotomy.

\section{Acknowledgment}

Dr Muhammed Tayyab Awan would like to thank Professors Tara Moore and Antonio Leccisotti, and also Shirley Sharron, of the University of Ulster for their support and guidance throughout the study and the writing of this paper.

\section{Disclosure}

All authors were involved in the planning, designing, and executing of the study reported herein, and in the writing of this paper. The authors have no conflicts of interest in this work.

\section{References}

1. Apple DJ. Influence of intraocular lens material and design on postoperative intracapsular cellular reactivity. Trans Am Ophthalmol Soc. 2000;98:257-283

2. Werner L, Apple DJ, Pandey SK. Postoperative proliferation of anterior and equatorial lens epithelial cells: a comparison between various foldable IOL designs. In: Buratto L, Osher RH, Masket S, editors. Cataract Surgery in Complicated Cases. Thorofare, NJ: Slack; 2000:399-417.

3. Zemaitiene R. Posterior capsule opacification: incidence and pathogenesis. Medicina (Kaunas). 2003;39(9):830-837. Lithuanian.

4. Spalton DJ. Posterior capsular opacification after cataract surgery. Eye (Lond). 1999;13(Pt 3b):489-492.

5. Awasthi N, Guo S, Wagner BJ. Posterior capsular opacification: a problem reduced but not yet eradicated. Arch Ophthalmol. 2009;127(4): 555-562.

6. Apple DJ, Peng Q, Visessook N, et al. Eradication of posterior capsule opacification: documentation of a marked decrease in Nd:YAG laser posterior capsulotomy rates noted in an analysis of 5416 pseudophakic human eyes obtained postmortem. Ophthalmology. 2001;108(3): 505-518.

7. Hayashi K, Hayashi H, Nakao F, Hayashi F. Posterior capsule opacification after cataract surgery in patients with diabetes mellitus. Am J Ophthalmol. 2002;134(1):10-16.

8. Polak M, Zarnowski T, Zagórski Z. Results of Nd:YAG laser capsulotomy in posterior capsule opacification. Ann Univ Mariae Curie Sklodowska Med. 2002;57(1):357-363.

9. Burq MA, Taqui AM. Frequency of retinal detachment and other complications after neodymium:Yag laser capsulotomy. J Pak Med Assoc. 2008;58(10):550-552.

10. Senne FM, Temporini ER, Arieta CE, Pacheco KD. Perception of difficulties with vision-related activities of daily living among patients undergoing unilateral posterior capsulotomy. Clinics (Sao Paulo). 2010;65(5):459-468. 
11. Tami R, Sellman TR, Lindstrom RL. Effect of a plano-convex posterior chamber lens on capsular opacification from Elschnig pearl formation. $J$ Cataract Refract Surg. 1988;14(1):68-72.

12. Venkatesh N, Prajna NV, Ellwein LB, Selvaraj S, Manjula K, Kupfer C. The Madurai Intraocular Lens Study IV: posterior capsule opacification. Am J Ophthalmol. 2000;130(3):304-309.

13. Aslam TM, Patton N. Methods of assessment of patients for Nd:YAG laser capsulotomy that correlate with final visual improvement. BMC Ophthalmol. 2004;4:13.

14. Steinert RF. Neodymium:yttrium-aluminum-garnet laser posterior capsulotomy. In: Steinert RF, editor. Cataract Surgery. 3rd ed. Philadelphia, PA: Saunders Elsevier; 2010:617-630.
15. Flach AJ, Dolan BJ. Incidence of postoperative posterior capsular opacification following treatment with diclofenac $0.1 \%$ and ketorolac 0.5\% ophthalmic solutions: 3-year randomized, double-masked, prospective clinical investigation. Trans Am Ophthalmol Soc. 2000;98: 101-107.

16. Hassan KS, Adhi MI, Aziz M. Nd:YAG laser posterior capsulotomy. Pak J Ophthalmol. 1996;12:3-7.

17. Steinert RF, Puliafito CA, Kumar SR, Dudak SD, Patel S. Cystoid macular edema, retinal detachment, and glaucoma after Nd:YAG laser posterior capsulotomy. Am J Ophthalmol. 1991;112(4):373-380.
Clinical Ophthalmology

\section{Publish your work in this journal}

Clinical Ophthalmology is an international, peer-reviewed journal covering all subspecialties within ophthalmology. Key topics include: Optometry; Visual science; Pharmacology and drug therapy in eye diseases; Basic Sciences; Primary and Secondary eye care; Patien Safety and Quality of Care Improvements. This journal is indexed on

Submit your manuscript here: http://www.dovepress.com/clinical-ophthalmology-journal

\section{Dovepress}

PubMed Central and CAS, and is the official journal of The Society of Clinical Ophthalmology (SCO). The manuscript management system is completely online and includes a very quick and fair peer-review system, which is all easy to use. Visit http://www.dovepress.com/ testimonials.php to read real quotes from published authors. 